\title{
Progeroid Syndrome with Mitral Regurgitation: A Rare Case Report
}

\author{
D. P. Kalyana Chakravarthi ${ }^{1}$ Yalampati Rama Kishore \\ ${ }^{1}$ Department of Cardiology, Nizam's Institute of Medical Sciences,
Hyderabad, Telangana, India
}

Ind J Car Dis Wom:2020;5:117-122

\section{Naveen Kumar ${ }^{1}$}

\begin{abstract}
Address for correspondence D. P. Kalyana Chakravarthi, DM, Department of Cardiology, Nizam's Institute of Medical Sciences, Hyderabad 500018, Telangana, India (e-mail: Kalyandoc04@gmail.com).
\end{abstract}

\begin{abstract}
Keywords

- mitral regurgitation

- progeria

Progeroid syndromes (PS) involve the disorder of early aging. Although survival of progeria syndrome patients is nearly 15 years as per literature, the adult onset progeroid starts manifesting in the third decade. Here, we are presenting a rare case of progeroid at the age of 45 years with mitral regurgitation (MR). The patient has alopecia, dry skin, frontal bossing, up staring eyes with bilateral corneal opacities, prominent nose with parrot beak appearance, thin upper lip, large, low-set ears, periorbital hyperpigmentation, micrognathia, retrognathia, and hyperpigmentation over lower abdomen/ both feet and hands. Facial and skeletal manifestation are the major clinical features of the PS; along with the characteristics mentioned above, the patient also had severe eccentric MR. This patient has PS with mitral valve prolapse and severe MR. Most of the features of progeria exist in this patient, which manifested at a younger age. However, the progression of the external features and survival up to 45 years favors PS instead of progeria. Therefore, genetic analysis is mandatory to confirm. We are reporting this case due to the rarity of onset of symptoms within a younger age group; however, the progression of the disease was very slow, which may be a another variant of progeria/PS.
\end{abstract}

\section{Introduction}

Progeroid syndromes (PS) involve the disorder of early aging. ${ }^{1}$ Neonatal variants of PS present at the time of birth include Hallerman-Streiff syndrome, Wiedemann-Rautenstrauch syndrome, and De Barsy syndrome. Other types include mandibulo-acral dysplasia (MAD) and Cockayne syndrome. Progeria is a type of PS. Although the survival of PS patients is around 15 years as per literature, the adult onset PS starts manifesting in the third decade. Here, we present a rare case of PS at the age of 45 years. In 1886, progeria was first described by Jonathan Hutchinson and Hastings Gilford. ${ }^{1}$ The classical variant of progeria is the Hutchinson-Gilford progeria syndrome (HGPS). It is a disorder of dwarfism and premature aging, ${ }^{2}$ with a slight preponderance among males, being 1.5 times higher than females, and common in Caucasians, with an incidence of one in eight million births. ${ }^{2}$ Inherited cases are rare, but de novo mutations are more common.
LMNA gene mutations are the main cause of many cases. ${ }^{3}$ These patients have characteristic facies. Morbidity and mortality mainly result from early atherosclerosis of coronary arteries, leading to premature death. ${ }^{4}$

\section{Case Report}

A 45-year-old male patient presented with poor vision at the age of 2 years, with history of loss of hair, eyebrows, and also eyelashes from 5 years of age, normal developmental history, and exertional shortness of breath of NYHA class II of 3 months which progressed to NYHA class III in 1 month. He was born out of nonconsanguineous marriage with normal birth history.

On examination, he has alopecia, dry skin, frontal bossing, up staring eyes with bilateral corneal opacities ( - Fig. 1; to show the corneal opacities, eyes were not covered),
C)2020 Women in Cardiology and Related Sciences
License terms

()(1) $\Theta \circledast$ 


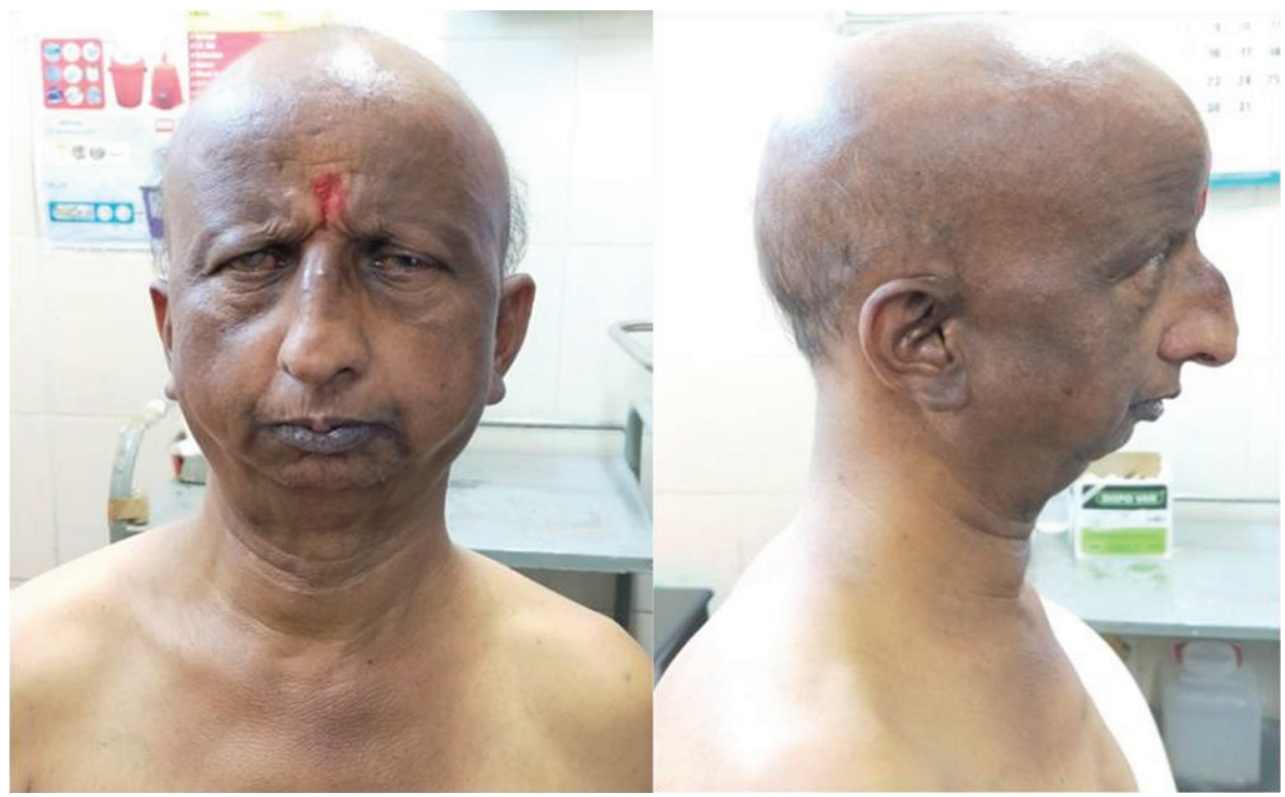

Fig. 1 External features of the progeroid syndrome patient.

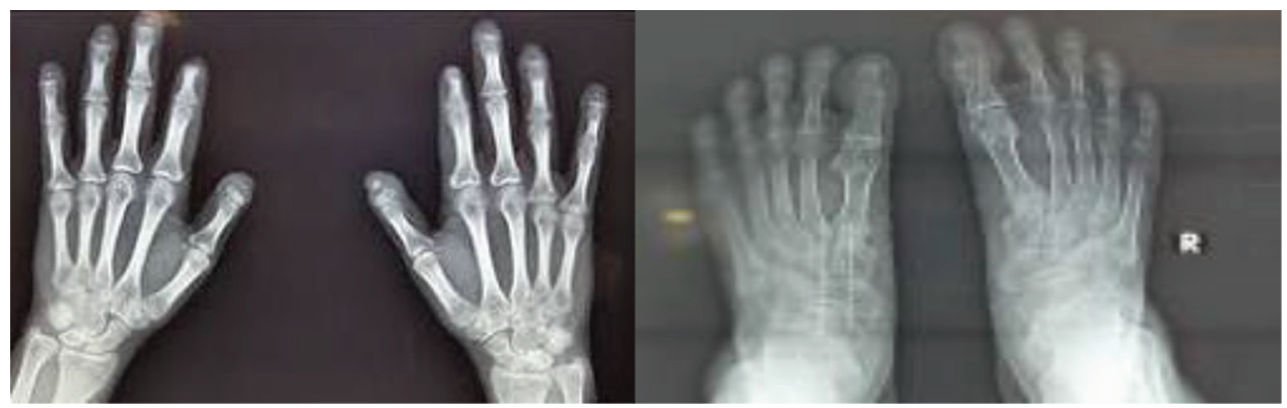

Fig. 2 Showing acral osteolysis of both fingers and toes.

prominent nose with parrot beak appearance, thin upper lip, large, low-set ears, periorbital hyperpigmentation, micrognathia, retrognathia, acral osteolysis of fingers and toes (-Fig. 2), hyperpigmentation over lower abdomen/both feet and hands, and clubbing (-Fig. 3 ).

According to history along with clinical examination, we initially suspected PS only. He has been known to be hypertensive since 3 years of age. Clinical and cardiovascular examination showed down and out LV type of apex, late systolic parasternal pulsations due to LA dilatation, systolic thrill at the apex, S1 is loud, S2 is wide variable spit, midsystolic click which is high pitched in nature, followed by late systolic murmur of grade $4 / 6$ at the apex radiating to axilla and back.

Routine blood investigations were within normal limits except lower high-density lipoprotein (HDL) cholesterol levels. His skull X-ray showed multiple wormian bones, diastasis of sagittal suture, and hypoplastic mandible with infantile angle. Chest X-ray showed thinning or ribbon-like ribs posteriorly, and both clavicles were short in length (- Fig. 4). Patient had mild conductive deafness for low-frequency voices present on auditory evaluation.

ECG suggestive of LA enlargement with LV volume overload and 2D echocardiogram showed myxomatous mitral valve with anterior mitral leaflet (AML) prolapse, causing severe eccentric mitral regurgitation (MR) (-Fig. 5). LV volumes were end diastole $125 \mathrm{~mL}$ and end systole $60 \mathrm{~mL}$. LV function was normal. There was no pulmonary arterial hypertension. Holter did not reveal any arrhythmias.

CAG and Cath data showed normal coronaries, myxomatous mitral valve, AML prolapsed, severe eccentric MR in normal sinus rhythm, good biventricular function, mild tricuspid regurgitation (TR), no pulmonary artery hypertension $(\mathrm{PAH})$, not in failure, and no signs of infective endocarditis (PCWP-10, PA-25/12(18), RV-30/0-10, RA-3, LVEDP 0-10, no gradient $\mathrm{b} / \mathrm{w}$ LV and aorta).

\section{Discussion}

Progeria is a rare genetic disorder characterized by premature aging. Aging is seven times more common than normal. Progeria is also called "Hutchinson-Gilford progeria syndrome" (HGPS). This HGPS, caused by mutation in the LMNA gene, is mostly transmitted by autosomal dominant genes, and rarely by autosomal recessive or maternal gonadal mosaicism. ${ }^{5}$ LMNA has laminins $\mathrm{A}$ and $\mathrm{C}$, which are not only an integral part of intermediate filamentous lamina but also 


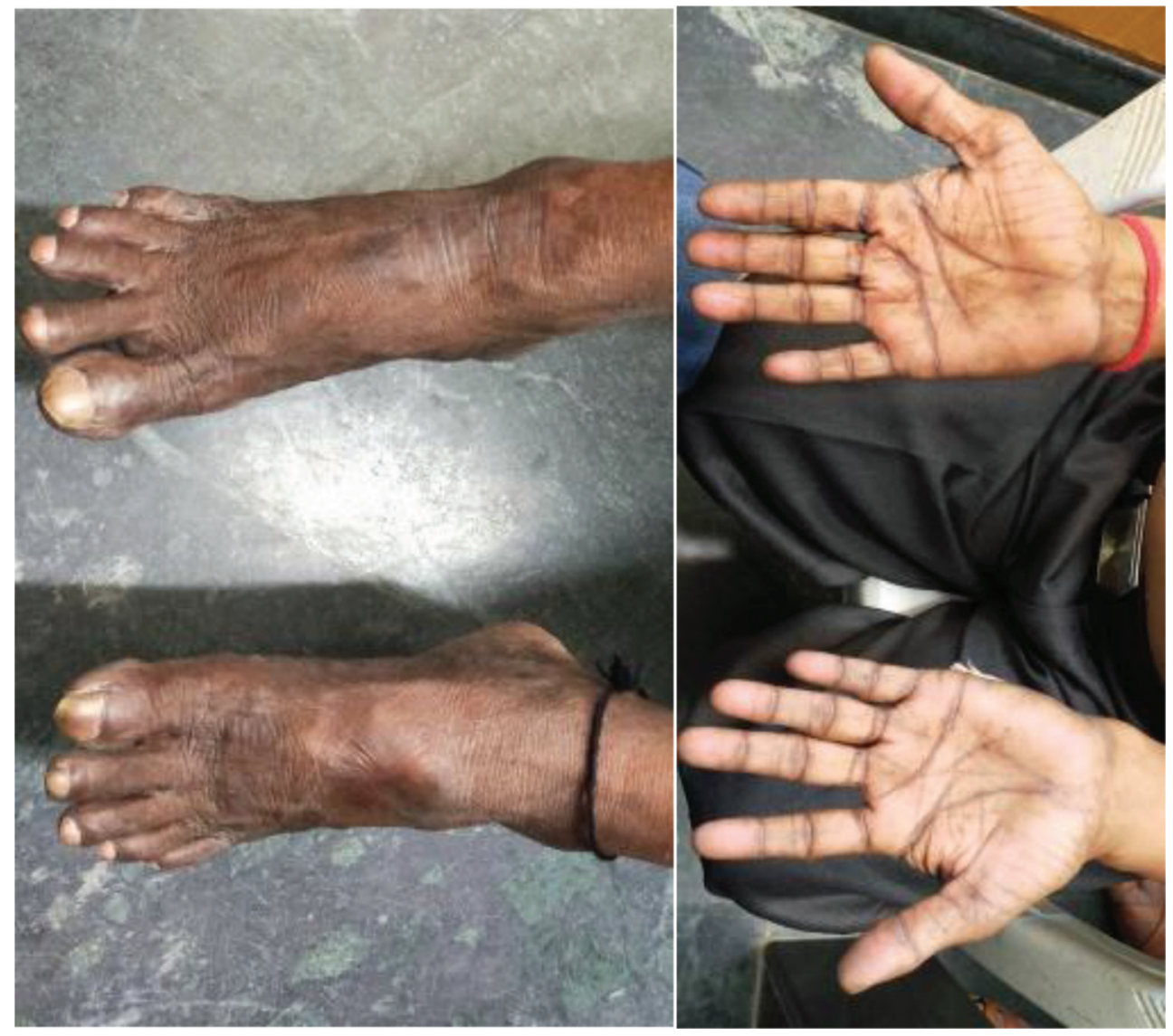

Fig. 3 Hyper pigmentation and clubbing of feet and hands.

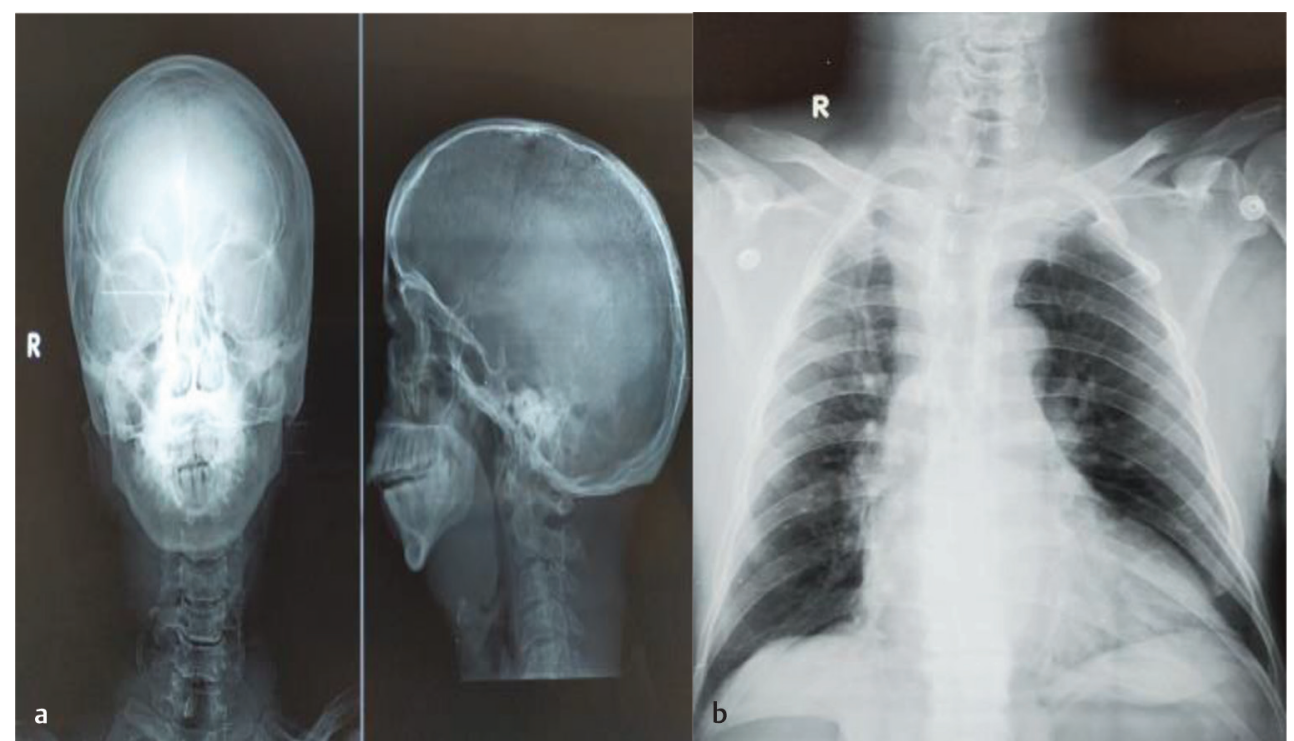

Fig. 4 Radiological abnormalities in (a) skull X-ray showing wormian bones and diastasis of sagittal suture, micrognathia, and mandibular infantile angle; (b) chest X-ray showing thinning or ribbon-like ribs posteriorly, and both clavicles were short in length.

provide structural support which, in turn, is useful for DNA replication and transcription of mRNA. ${ }^{6}$ The average lifespan of a progeria patient is 13 years (range $8-27$ years); very occasionally, they may survive till the age of 45 years. HGPS is part of PS. In progeria patients, hypertension may develop, but arteriosclerosis less likely, and the only lipid abnormality is decreased levels of HDL cholesterol. ${ }^{7}$
The affected patients will grow normally till the first year; later, they will develop hair loss and skin will show scleroderma-like changes with loss of subcutaneous fat which leads to "plucked bird" appearance. ${ }^{8}$ There is also loss of scalp hair and eyelashes. Progressive changes are also seen in skeleton and blood vessels along with advancing age. These patients' calvarium is thin, small face, and small mandible with infantile 


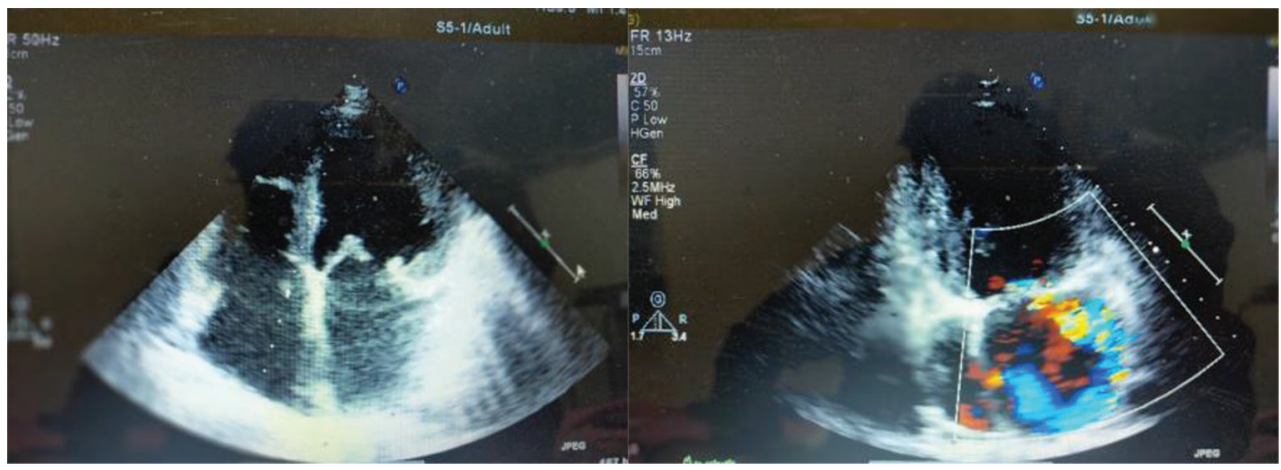

Fig. 5 Myxomatous mitral valve with anterior mitral leaflet prolapsed, and severe eccentric mitral regurgitation.

obtuse angle. ${ }^{9}$ Wormian bones are present in calvaria. The clavicles are small at the time of birth; during childhood, they may disappear because of osteolysis and fibrosis. Ribs are fragile and the bilateral posterior part of the upper four ribs may disappear in early childhood. ${ }^{10}$ Skeletal deformity includes coxa valga, and acro-osteolysis may develop. ${ }^{11}$

In PS, many of the above said features are also seen, but manifestations start at a later age. Early sign usually recognized is short stature, as in this case also, which begins during the teenage years. In early 20s, skin atrophy, subcutaneous fat loss, and graying of hair starts. However, for our index case, all features started early, but progression was very slow. Bilateral cataracts and hypogonadism are the additional features along with early appearance of DM and atherosclerosis. This patient is near blind due to diffuse corneal opacities, but no DM and no coronary atherosclerosis. Patient has been known to be hypertensive since 3 years of age, which may be essential or due to premature arteriosclerosis. This patient's clinical features and radiological findings confirm the provisional diagnosis. In progeria, the most common dyslipidemia finding is decreased levels of HDL cholesterol, as seen in our patient. Our patient had peculiarly presented at an advanced age, with severe mitral valve eccentric mitral regurgitation. Basically, the main pathology of progeria and other PS patients involves intermediate filamentous lamina, which plays a role in withstanding mechanical stress, especially cardiac and skeletal muscles. ${ }^{12}$ This leads to LV dysfunction which is most commonly seen in these patients and increases with age. ${ }^{13}$ Valvular involvement is also mostly seen in mitral and aortic valve stenosis or regurgitation. Annular and chordal calcification leads to mitral valve stenosis which is common than regurgitation. ${ }^{14}$ In our index patient, mitral valve regurgitation is seen, which is a very rare finding in progeroid syndrome patients.

Normally, in progeria patients, death occurs due to cardiovascular complications like myocardial infarction (MI) because of early atherosclerosis or heart failure caused by $\mathrm{LV}$ dysfunction. ${ }^{14}$

\section{Differential Diagnosis}

Differential diagnosis of progeria includes scleroderma, Werner syndrome, ectodermal dysplasia, Cockayne syndrome, Rothmund-Thomson syndrome, and acrogeria.
Table 1 Comparing HGPS and Werner syndrome features

\begin{tabular}{|c|c|c|}
\hline Variables & HGPS syndrome & Werner syndrome \\
\hline Age of onset & $\begin{array}{l}\text { Normal at birth, but } \\
\text { failure to thrive occurs } \\
\text { during the first year. }\end{array}$ & $\begin{array}{l}\text { Normal at birth, until } \\
\text { the end of the first } \\
\text { decade. Lack of a } \\
\text { growth spurt seen } \\
\text { in early teen years. } \\
\text { Symptoms typically } \\
\text { start in the 20s. }\end{array}$ \\
\hline $\begin{array}{l}\text { Life } \\
\text { expectancy }\end{array}$ & $\begin{array}{l}14 \text { years average, } \\
\text { range } 7 \text { to } 27 \text { years }\end{array}$ & 48 to 54 years \\
\hline Sex & $\begin{array}{l}\text { Both are affected } \\
\text { with slight male } \\
\text { predominance } 1.5: 1\end{array}$ & Male to female $1: 1$ \\
\hline $\begin{array}{l}\text { Clinical } \\
\text { features }\end{array}$ & $\begin{array}{l}\text { Large face, narrow } \\
\text { nasal ridge and tip, } \\
\text { thin vermilion of } \\
\text { the upper and lower } \\
\text { lips, small mouth, } \\
\text { and retro- and } \\
\text { micrognathia. } \\
\text { Subcutaneous fat } \\
\text { loss, delayed eruption } \\
\text { and loss of primary } \\
\text { teeth, alopecia, nail } \\
\text { dystrophy, and coxa } \\
\text { valga. }\end{array}$ & $\begin{array}{l}\text { Loss and graying of } \\
\text { hair, hoarseness of } \\
\text { voice, scleroderma- } \\
\text { like skin changes, } \\
\text { bilateral cataracts, } \\
\text { diabetes mellitus } \\
\text { (type 2), } \\
\text { hypogonadism, } \\
\text { chronic skin ulcers, } \\
\text { osteoporosis of bones, } \\
\text { and predisposed to } \\
\text { cancer. }\end{array}$ \\
\hline $\begin{array}{l}\text { Mental } \\
\text { development }\end{array}$ & Normal & Normal \\
\hline Gene & LMNA & WRN \\
\hline Transmission & $\begin{array}{l}\text { Sporadic autosomal } \\
\text { dominant }\end{array}$ & Autosomal recessive \\
\hline $\begin{array}{l}\text { Cause of } \\
\text { death }\end{array}$ & $\begin{array}{l}\text { Atherosclerosis, Ml } \\
\text { and stroke }\end{array}$ & Mainly by cancer or MI \\
\hline
\end{tabular}

Abbreviations: HGPS, Hutchinson-Gilford progeria syndrome; MI, myocardial infarction.

In this case, Cockayne syndrome was ruled out by absence of photosensitivity, facial erythema, and defects in eyes. Rothmund-Thomson syndrome patients have erythema, poikiloderma, and cataract. Acrogeria is also seen at birth, but only extremities were involved, with no atheroma or decrease in life expectancy. The triad of conical teeth, hypotrichosis, and anhidrosis, seen in hypohidrotic ectodermal dysplasia, was absent in our patient.

Here, we mention the major differences between classical HGPS progeria and Werner syndrome (-Table 1). 
MAD is a progeroid syndrome consisting of mainly two types. Type A is characterized by short stature, loss of fat in the extremities but accumulation of fat in the neck and trunk, hyperpigmented skin, partial alopecia, prominent eyes, convex nasal ridge, loss of tooth, micrognathia, retrognathia, and very short fingers. Type $B$ has generalized loss of subcutaneous fat and insulin resistance. Genes involved are MAD type A LMNA and type B ZMPSTE24, respectively, both of which are transmitted autosomal recessively. ${ }^{15}$

Our patient had clinical features which are typical, hence they are sufficient for the diagnosis. Low HDL cholesterol levels and typical skeletal features confirmed the diagnosis. This case is reported by us because of its rare nature.

\section{Management}

Marian et al reported a rare, nonsyndromic cardiac progeria case. They found a genomic variant p.Asp 300Asn in the LMNA gene, causing progressive degeneration, which is similar to progeroid syndromes. However, this syndrome involved the heart and not the other organs which are seen in the elderly. This patient had coronary artery disease for which coronary artery bypass surgery and subsequent percutaneous coronary interventions were conducted. Later, the patient developed MR. ${ }^{16}$ In our case, genetic analysis was not carried out.

Guo et al published in the Canadian Journal of Cardiology 2016. They represented a female patient with features of both dilated cardiomyopathy (DCM) and atypical progeroid syndrome. The de novo mutation detected on LMNA gene is p.Leu59Val which is located in LMNAc.175C $>$ CG. ${ }^{17,18}$ Index case does not have DCM.

A recent study done by Leslie et al looked into the role of lonafarnib (protein farnesyl transferase inhibitor) versus placebo in patients suffering from progeria. The study included 238 patients and it showed lonafarnib monotherapy compared with placebo was associated with a lower mortality rate during 2.2 years of follow-up. ${ }^{19}$

Problems during surgical management of this patient include intubation, maintenance of airway during anesthesia, and choice of mitral valve repair. As he has significant micrognathia, there may be problem in endotracheal intubation which may require ultrasonic-guided intubation or fiberoptic nasopharyngeal intubation. ${ }^{20}$ Preoperative analysis of mitral valve prolapse is more important to achieve good results, so mitral valve repair is mainly divided as gradings. ${ }^{21}$ There are mainly four grades, Grade 1 includes either annular dilatation or focal single-segment prolapse that is treated by triangular resection or PTFE neochords and annuloplasty. Grade 2 involves multiscallop involvement (clefts and myxoid leaflets) of posterior mitral leaflet (PML) with no or minimal involvement of the AML, which requires some part of PML height reduction. Grade 3 involves bileaflet, myxomatous AML or several segments of both leaflets. Grade 4 had complex MAC that may require some resection and annular reconstruction. ${ }^{21-24}$

In our patient, prolapse of anterior leaflet is seen, with grade 3 disease, so surgery is more complex and requires intense surgical expertise. Generally, to correct AML prolapse caused by a ruptured or elongated chord, surgeon will create new Gore-Tex chords. Otherwise, the second option for correction of AML prolapse is chordal transfer. Both methods will provide excellent long-term results.

In conclusion, this patient has progeroid syndrome with mitral valve prolapse and severe mitral regurgitation. Most of the features of progeria are there in this patient which were manifested at a younger age. But the progression of the external features and survival up to 45 years favors progeroid syndrome instead of progeria. Therefore, genetic analysis is mandatory to confirm. We are reporting this case due to the rarity of onset of symptoms within a younger age group, but progression of the disease was very slow, which may be a another variant of progeria/PS.

\section{Conflict of Interest}

None.

\section{References}

1 Hennekam RCM. Hutchinson-Gilford progeria syndrome: review of the phenotype. Am J Med Genet A 2006;140(23): 2603-2624

2 Cenni V, D’Apice MR, Garagnani P, et al. Mandibuloacral dysplasia: a premature ageing disease with aspects of physiological ageing. Ageing Res Rev 2018;42:1-13

3 Pollex RL, Hegele RA. Hutchinson-Gilford progeria syndrome. Clin Genet 2004;66(5):375-381

4 Stehbens WE, Wakefield SJ, Gilbert-Barness E, Olson RE, Ackerman J. Histological and ultrastructural features of atherosclerosis in progeria. Cardiovasc Pathol 1999;8(1):29-39

5 Gordon CM, Gordon LB, Snyder BD, et al. Hutchinson-Gilford progeria is a skeletal dysplasia. J Bone Miner Res 2011;26(7): 1670-1679

6 Brown WT. Human mutations affecting aging-a review. Mech Ageing Dev 1979;9(3-4):325-336

7 Badame AJ. Progeria. Arch Dermatol 1989;125(4):540-544

8 Ding SL, Shen CY. Model of human aging: recent findings on Werner's and Hutchinson-Gilford progeria syndromes. Clin Interv Aging 2008;3(3):431-444

9 DeBusk FL. The Hutchinson-Gilford progeria syndrome. Report of 4 cases and review of the literature. J Pediatr 1972;80(4): 697-724

10 Merideth MA, Gordon LB, Clauss S, et al. Phenotype and course of Hutchinson-Gilford progeria syndrome. N Engl J Med 2008;358(6):592-604

11 Hamer L, Kaplan F, Fallon M. The musculoskeletal manifestations of progeria. A literature review. Orthopedics 1988;11(5): 763-769

12 Bloom S, Lockard VG, Bloom M. Intermediate filament-mediated stretch-induced changes in chromatin: a hypothesis for growth initiation in cardiac myocytes. J Mol Cell Cardiol 1996;28(10):2123-2127

13 Sylvius N, Tesson F. Lamin A/C and cardiac diseases. Curr Opin Cardiol 2006;21(3):159-165

14 Prakash A, Gordon LB, Kleinman ME, et al. Cardiac abnormalities in patients With Hutchinson-Gilford progeria syndrome JAMA Cardiol 2018;3(4):326-334

15 Garavelli L, D'Apice MR, Rivieri F, et al. Mandibuloacral dysplasia type A in childhood. Am J Med Genet A 2009;149A(10):2258-2264

16 Marian AJ.. Non-syndromic cardiac progeria in a patient with the rare pathogenic p.Asp300Asn variant in the LMNA gene BMC Med Genet 2017;18:116 
17 Brayson D, Shanahan CM. Current insights into LMNA cardiomyopathies: existing models and missing LINCs. Nucleus 2017; 8(1):17-33

18 Worman HJ. Cell signaling abnormalities in cardiomyopathy caused by lamin $\mathrm{A} / \mathrm{C}$ gene mutations. Biochem Soc Trans 2018;46(1):37-42

19 Gordon LB, Shappell H, Massaro J, et al. Association of lonafarnib treatment vs no treatment with mortality rate in patients with Hutchinson-Gilford progeria syndrome. JAMA 2018;319(16):1687-1695

20 Chowdhury AR, Punj J, Pandey R, Darlong V, Sinha R, Bhoi D. Ultrasound is a reliable and faster tool for confirmation of endotracheal intubation compared to chest auscultation and capnography when performed by novice anaesthesia residents - A prospective controlled clinical trial. Saudi J Anaesth 2020;14(1):15-21
21 Tatum JM, Bowdish ME, Mack WJ, et al. Outcomes after mitral valve repair: A single-center 16-year experience. J Thorac Cardiovasc Surg 2017;154(3):822-830.e2

22 Mazine A, Friedrich JO, Nedadur R, et al. Systematic review and meta-analysis of chordal replacement versus leaflet resection for posterior mitral leaflet prolapse. J Thorac Cardiovasc Surg 2018;155(1):120-128.e10

23 Thomas MP, Badhwar V. A three-step technique for repair of rheumatic disease of the mitral valve. Cardiol Young 2014;24(6):1104-1107

24 Badhwar V, Peterson ED, Jacobs JP, et al. Longitudinal outcome of isolated mitral repair in older patients: results from 14,604 procedures performed from 1991 to 2007. Ann Thorac Surg 2012;94(6):1870-1877, discussion 1877-1879 